\title{
Krüppel-like factor 4 is widely expressed in the mouse male and female reproductive tract and responds as an immediate early gene to activation of the protein kinase A in TM4 Sertoli cells
}

\author{
M Godmann ${ }^{1}$, C Kosan ${ }^{2}$ and R Behr ${ }^{1,3}$ \\ ${ }^{1}$ Institute of Anatomy, Developmental Biology and ${ }^{2}$ Institute of Cell Biology, University of Duisburg-Essen Medical \\ School, Hufelandstrasse 55, 45122 Essen, Germany and ${ }^{3}$ Department of Stem Cell Biology, German Primate Center, \\ Kellnerweg 4, D-37077 Göttingen, Germany \\ Correspondence should be addressed to R Behr at Department of Stem Cell Biology, German Primate Center; Email: rbehr@dpz.eu
}

M Godmann is now at Department of Animal Science, McGill University, Macdonald Campus, 21111 Lakeshore Road, Ste-Annede-Bellevue, Quebec, Canada H9X 3V9

C Kosan is now at Institut de Recherches Cliniques de Montréal, 110 Avenue des Pins Ouest, Montréal, Quebec, Canada H2W 1R7

\begin{abstract}
Krüppel-like factor 4 (KLF4) is a zinc finger transcription factor critically involved in cell proliferation, differentiation, and carcinogenesis. Recently, KLF4 has also been used for the generation of induced pluripotent stem cells. In this study, we analyzed KIf4 expression in different mouse tissues using northern blot analysis and immunohistochemistry. Focusing on the male and female reproductive tract, we showed for the first time that KLF4 is expressed in the epithelia of the murine uterus and the vagina. In the male reproductive tract, we detected KLF4 in the epithelia of the epididymis, ductus deferens, coagulating gland, and the penis. As KLF4 is strongly inducible by FSH signaling in Sertoli cells and as this transcription factor is also involved in Sertoli cell development, we employed the mouse Sertoli cell line TM4 as a model system to investigate i) the induction kinetics of Klf4 upon activation of the cAMP/protein kinase A pathway by forskolin and ii) the effects of Klf4 induction on TM4 cell cycle progression. Interestingly, Klf4 mRNA and protein were rapidly but transiently induced, reaching peak levels after 90-120 min and declining to basal levels within $4 \mathrm{~h}$. Compared with the inducible cAMP early repressor, an immediate early response gene, the induction kinetics of Klf4 is much faster. In conclusion, KIf4 is an immediate early gene in TM4 cells and its expression in several epithelia of the male and female reproductive tract suggests an important role of $\mathrm{Klf} 4$ in mouse reproductive functions.

Reproduction (2010) 139 771-782
\end{abstract}

\section{Introduction}

Krüppel-like factor 4 (KLF4) is a zinc finger transcription factor involved in terminal differentiation and cell cycle regulation of different types of epithelial cells (Garrett-Sinha et al. 1996, Shields et al. 1996, Segre et al. 1999, Katz et al. 2002, 2005, Chen et al. 2003, Dang et al. 2003). Klf4 has also been characterized as a tumor suppressor gene since its endodermal deletion caused precancerous changes in the epithelium of the adult stomach (Katz et al. 2005), and it is also involved in colorectal cancer (Dang et al. 2000, Zhao et al. 2004, Ghaleb et al. 2007). Moreover, Klf4 can act as an oncogene (Rowland et al. 2005). Whether Klf4 functions as a tumor suppressor or an oncogene depends on the molecular context in which KLF4 acts (Rowland \& Peeper 2006). Klf4 mRNA is highly abundant in the stomach, colon, and skin as well as in other tissues (Garrett-Sinha et al. 1996, Shields et al. 1996, Panigada et al. 1999, Segre et al. 1999, Swamynathan et al. 2007). Lack of the mouse KLF4 protein in the skin results in loss of the skin barrier function, which leads to early postnatal death (Segre et al. 1999). Moreover, the absence of KLF4 in the epithelium of the developing gut leads to a dramatic reduction in the number of goblet cells in the colon (Katz et al. 2002).

Remarkably, KLF4 has also been shown to be crucially involved in the maintenance of pluripotency in embryonic stem cells (Li et al. 2005, Jiang et al. 2008) and in the induction of pluripotency in fibroblasts, i.e. generation of induced pluripotent stem cells (Okita et al. 2007, Wernig et al. 2007). This clearly demonstrates a not yet fully characterized ambivalent role of KLF4 in terminally differentiated cells on the one hand and in highly proliferative undifferentiated cells on the other hand.

In the male germinal epithelium, the somatic Sertoli cell represents a unique epithelial cell with highly specialized functions, since the so-called nurse cell is 
responsible for germ cell survival and differentiation (Mruk \& Cheng 2004). Any disturbance of Sertoli cell differentiation can impair proper Sertoli cell function and thus male germ cell development (Mason et al. 1986, Raymond et al. 2000, Myers et al. 2005).

Recently, we have demonstrated that KIf4 is strongly expressed in spermatids in the mouse (Behr \& Kaestner 2002, Godmann et al. 2005, 2009b) and human (Behr et al. 2007) testis. Interestingly, we found that KIf4 is also strongly expressed in human seminoma and sometimes also in human fetal gonocytes (Godmann et al. 2009a). Furthermore, our results and other studies showed that KIf4 is also expressed in testicular Sertoli cells (Hamil \& Hall 1994, McLean et al. 2002, Sadate-Ngatchou et al. 2004, Godmann et al. 2008). Cell type-specific deletion of Klf4 in Sertoli cells demonstrated a significant role of Klf4 during Sertoli cell differentiation (Godmann et al. 2008). Interestingly, in a primary Sertoli cell culture, KIf4 was induced several hours after FSH stimulation (McLean et al. 2002, Sadate-Ngatchou et al. 2004). FSH action is characterized by its stimulation of the adenylyl cyclase/cAMP pathway via activation of a G protein-coupled receptor (Loss et al. 2007). Briefly, binding of hormones to $G$ protein-coupled receptors results in the activation of the adenylyl cyclase. This, in turn, results in an increase of intracellular levels of CAMP. CAMP binds to the regulatory subunit of the heterotetrameric protein kinase A (PKA) and causes the release of the catalytic subunit, which can migrate into the nucleus and activate target proteins by phosphorylation. Among these PKA targets are the transcription factors CREM and CREB, which are essential for many cellular processes and especially for testicular function (Don \& Stelzer 2002, Monaco et al. 2004). The CREM isoform inducible cAMP early repressor, ICER, which is generated from an internal Crem gene promoter (Molina et al. 1993), has been shown to be very rapidly inducible upon activation of the cAMP/PKA signal transduction pathway in testicular Sertoli cells (Monaco et al. 1995). Depending on the cells investigated the peak of ICER mRNA levels was observed 2-4 $\mathrm{h}$ after activation of the CAMP/PKA pathway. Thus, the kinetics of ICER induction in Sertoli cells corresponds to an early response gene (Monaco et al. 1995).

While strong KIf4 expression has been reported for some adult tissues including skin, colon, and testis, numerous other cell types and epithelia have not yet been tested for KLF4 expression including the entire male (besides testis) and female reproductive tract. The first aim of the present study was to investigate KLF4 expression in distinct, not yet analyzed, adult murine epithelia of the male and female reproductive tract. Secondly, we focused on the established testicular TM4 Sertoli cell line (Mather 1980), and analyzed the kinetics of Klf4 induction and its influence on the Sertoli cell cycle. We used the TM4 cell line to investigate i) the kinetics of Klf4 induction on the mRNA and protein levels; ii) whether the induction of Klf4 indeed depends on the activation of the cAMP/PKA signal transduction pathway, as suggested by the FSH induction of Klf4 in primary Sertoli cells; and iii) whether PKA-dependent induction of KIf4 has an effect on cell cycle progression in TM4 cells.

\section{Results \\ KLF4 is expressed in epithelia of the male reproductive tract}

We have previously shown that KLF4 is expressed in round spermatids and in Leydig cells in the mouse testis (Behr \& Kaestner 2002, Godmann et al. 2009b). In the present study, we show by immunohistochemistry that KLF4 is strongly but gradually expressed in the epididymis (Fig. 1A) reflecting the different regions of the epididymis, i.e. caput, corpus, and cauda (Johnston et al. 2005). Most epithelial cells of the proximal caput of the epididymis showed only very faint signals. Only few scattered cells were clearly stained. The nuclei of these cells were located rather apically (Fig. 1A and B). These cells were narrow cells, thought to be absorptive rather than secretory. The distal part of the caput epididymis showed stronger staining compared with the proximal caput. Intense cytoplasmic as well as nuclear staining was visible. Only very few cells were not stained. The corpus epididymis showed the strongest staining of all epididymal regions with very intense signals in almost all nuclei and also in the cytoplasm (Fig. 1C). Like in the distal caput, only few cells were not stained. The caudal region of the epididymis was still KLF4 positive, but the staining was less intense compared with the epididymal corpus (Fig. 1D). The cytoplasm of all cells was homogenously stained. In contrast, there were clear differences in the nuclear signals with the minority of nuclei exhibiting only faint or even no signals (Fig. 1D). The vas deferens also showed clear staining of the epithelium (Fig. 1E). The cytoplasm of all epithelial cells was stained. In contrast, only a part of the nuclei of all epithelial the cells was KLF4 positive. The stromal tissue and sperm cells in the lumen were, like in the epididymis, not stained. Figure $1 \mathrm{~F}$ shows the corresponding negative control. Figure $1 \mathrm{G}$ shows the epithelium of the prostate and underlying adipose tissue. The epithelium exhibits weak staining in only a few cells, preferentially those cells lining the plicae. Interestingly, the soma and nuclei of the fat cells were strongly KLF4 positive as reported recently (Sun et al. 2009). In the coagulating gland, also called anterior prostate, mostly those epithelial cells lining the intraluminal folds were stained (Fig. $1 \mathrm{H}$ ). Almost all these cells showed intensive staining of the apical cytoplasm, while the basal areas were clearly less stained. Irrespective of the cytoplasmic signals, the nuclei were either strongly stained or unstained (Fig. $1 \mathrm{H})$. The seminal vesicles showed no 
staining - neither in the epithelium nor in the stroma (Fig. 1I). The epithelia of the penis exhibited strong signals with restriction of the staining to the nuclei. Some of the stromal cells as well as chondrocytes were also stained (Fig. 1J-L).
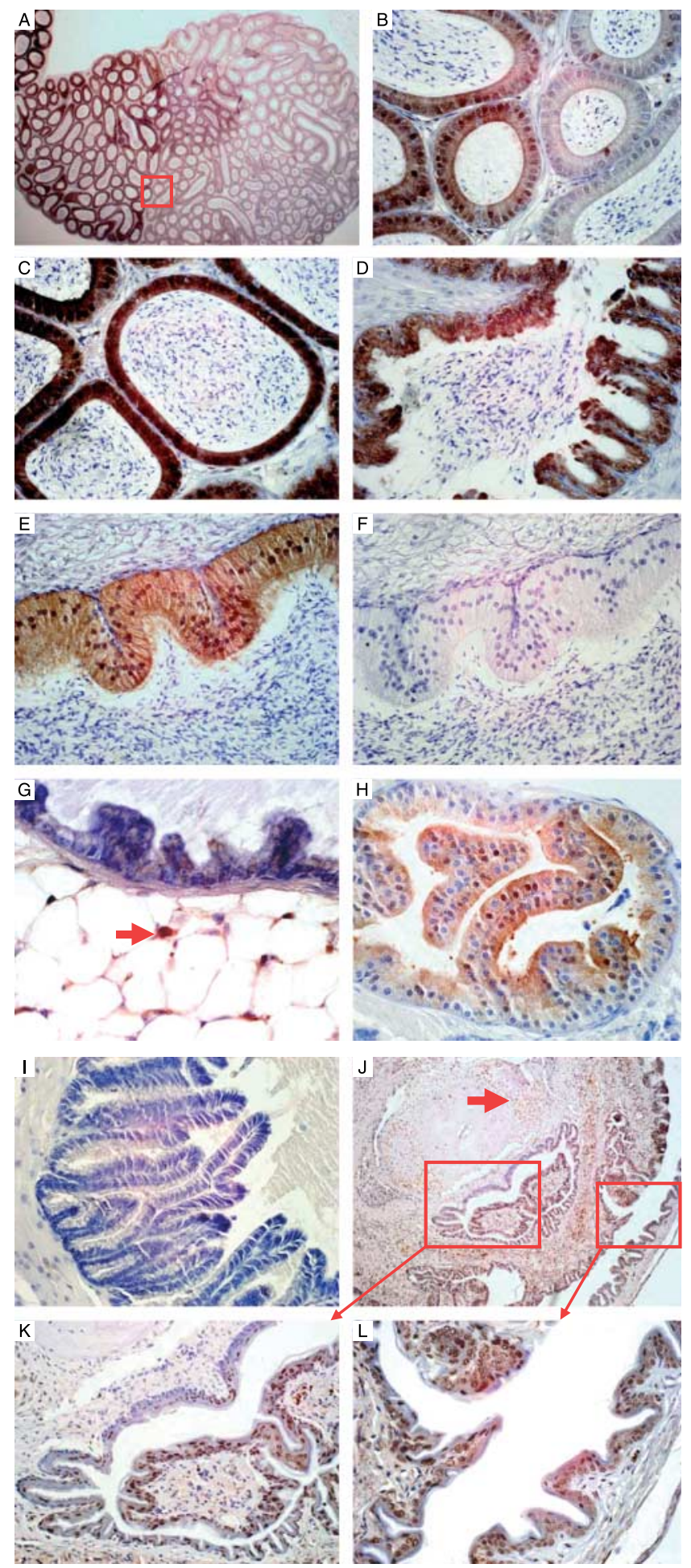

\section{KLF4 is expressed in distinct epithelia of the female reproductive tract}

In the female reproductive tract, we obtained similar results with both KLF4 antibodies for the uterine epithelium (endometrium) and the vaginal epithelium (Fig. 2). Both epithelia, although histologically very different, showed clear nuclear staining in a subpopulation of cells. Interestingly, a significant population of cells in both epithelia was devoid of KLF4 antigenicity. The expression of KLF4 in the uterine epithelium may also depend on the stage of the reproductive cycle of the animals since not all specimens tested exhibited KLF4 signals (three of seven positive; Fig. 2A). However, the stage of the reproductive cycle of the mice was not determined when the tissue was fixed. Remarkably, in the vaginal epithelium, the proportion of stained cells was higher in the basal area of the epithelium than in the apical area, where differentiating cells are located (Fig. 2C). This is in contrast to other epithelia like the skin or the tongue, where the percentage of KLF4positive cells and the intensity of the staining increased in the apical, terminally differentiating cell layers.

Using the KLF4 antibody from Santa Cruz Biotechnology (Santa Cruz, CA, USA), we also obtained staining in the cytoplasm of oocytes, granulosa cells, cells of the corpus luteum, in a subset of cells of the epithelium of the oviduct (cytoplasmic and nuclear staining), trophoblast cells, and some blood cells in the placenta (data not shown). However, this staining could not be reproduced with the antibody from R\&D Systems (Minneapolis, MN, USA) and was therefore not considered as sufficiently validated. Furthermore, the control stainings using normal rabbit sera sometimes resulted in similar staining patterns

Figure $1 \mathrm{KLF} 4$ protein expression in male reproductive tissues. (A) Overview over the caput epididymis, where staining can be seen mainly in the epithelium of the distal caput. A clear difference in the staining intensity can be seen between different regions. (B) Magnification of the boxed detail from (A). A connective tissue string separates the area exhibiting low stain intensity from those showing high intensity. (C) Strongly stained epithelium from the epididymal corpus. Sperm cells and almost all stromal cells are not stained. (D) Cauda of the epididymis. Again, most of the epithelial cells show strong nuclear and cytoplasmic staining. Only few cells located within the epithelium are not stained. (E) Vas deferens showing staining of the epithelium. While the cytoplasm of all epithelial cells appears to be stained, only a subset of the nuclei of all epithelial the cells was strongly KLF4 positive.

The other half is unstained. Underlying stromal cells and sperm cells in the lumen are not stained. (F) Negative control of (E). (G) Epithelium of the prostate and underlying adipose tissue. The epithelium exhibits weak staining in a subset of cells. Interestingly, the fat cells are strongly KLF4 positive (red arrows). (H) Coagulating gland (anterior prostate). Mostly those epithelial cells lining the intraluminal folds are stained. (I) The seminal vesicle shows no staining. (J) Overview over a cross section of the penis. Boxed areas are magnified in $(\mathrm{K})$ and $(\mathrm{L})$ respectively. (K) Within the epithelial cells, KLF4 protein is completely restricted to the nuclei. Some of the stromal cells as well as chondrocytes (red arrow in J) in the hyaline growth cartilage next to the os penis are also stained. (L) Epithelium of the skin of the glans penis. For further details, see the Results section. Primary magnifications: $400 \times$. 

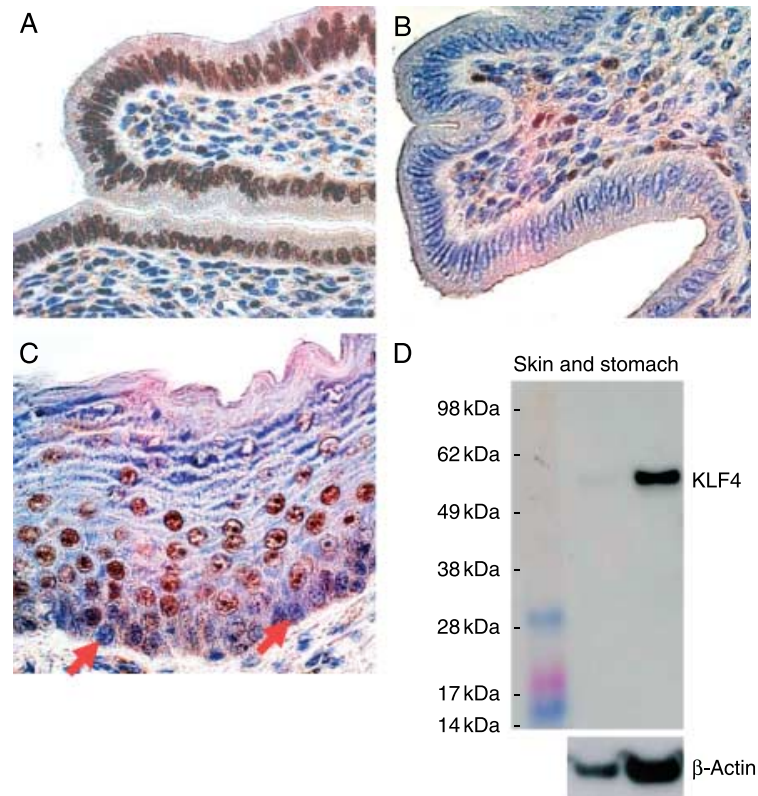

Figure 2 KLF4 expression in the female reproductive tract. (A) Strong nuclear staining of epithelial cells of the uterine endometrium. (B) Negative control for (A). (C) The vaginal epithelium exhibits numerous KLF4-positive cells, especially in the basal area of the epithelium. Staining is restricted to the nuclei. Basal cells in contact with the basal lamina are mostly KLF4 negative (red arrows). (D) KLF4 western blot of protein isolated from mouse skin and stomach using the antibody obtained from R\&D Systems. The antibody detects one specific band migrating around the expected size of $53 \mathrm{kDa}$.

as obtained with the Santa Cruz antibody, suggesting an unspecific binding of this antibody in immunohistochemistry on paraffin-embedded tissue sections. The specificity of the anti-KLF4 antibody obtained from R\&D Systems was confirmed by western blot analysis on total protein extracts isolated from mouse skin and stomach. The antibody detected only one specific band in both tissue samples (Fig. 2D) validating its specificity.

Northern blot analysis of Klf4 expression in the uterus further strengthened our results obtained by immunohistochemistry (Fig. 3). Although the mRNA levels are relatively low compared with the colon (which exhibited highest relative KIf4 levels in this study), a clear and distinctive Klf4 signal was obtained in the uterus. Since we detected KIf4 mRNA also in the placenta, it remains to be elucidated whether the mRNA is translated and, if yes, where the KLF4 protein is localized (see above). As demonstrated previously and confirmed in Fig. 3, KIf4 mRNA is abundant in the skin (Segre et al. 1999) as well as in several endodermal tissues including the stomach, the colon, and the lungs (Garrett-Sinha et al. 1996, Shields et al. 1996). By immunohistochemistry, we also detected KLF4 in the course of the present investigation in the mucosa of the oral cavity, the respiratory epithelium, the esophagus, the sigmoid, as well as in the epithelium of the cornea. Interestingly, also chondrocytes of the trachea were clearly stained (data not shown).

\section{KLF4 protein is induced by forskolin as revealed by immunofluorescence}

In the recent study, we have described Klf4 expression in the murine male and female reproductive tract. Next, we were interested in how Klf4 expression is induced. Since Klf4 has been shown to be up-regulated in primary Sertoli cell culture (Hamil \& Hall 1994, McLean et al. 2002) and in the testis of hypogonadal mice (Sadate-Ngatchou et al. 2004) several hours after FSH stimulation, we chose the TM4 Sertoli cell line as a model system. It has been shown that TM4 cells do not respond to FSH (Monaco et al. 1995). This is probably due to low FSH receptor expression in this cell line (Mather 1980) or even undetectable FSH receptor levels (own unpublished RT-PCR data). However, we used forskolin instead of simulating the FSH and activating the cAMP/PKA pathway and testing whether KIf4 can also be induced in this epithelial TM4 Sertoli cell line (Mather 1980). Forskolin activates the adenylyl cyclase. This enzyme increases intracellular cAMP levels. High cAMP levels result in an activation of the PKA, which, in turn, phosphorylates its target proteins. As controls, we added only growth medium or growth medium plus DMSO (the solvent for forskolin) to cell cultures treated in the same way. We first checked by immunofluorescence (IF) whether KLF4 protein was up-regulated after the addition of forskolin. As shown in Fig. 4, $1 \mathrm{~h}$ after the addition of forskolin, we performed IF and could detect a clear induction of KLF4 protein (Fig. 4C, best visible in the merged picture), while untreated control cells

A

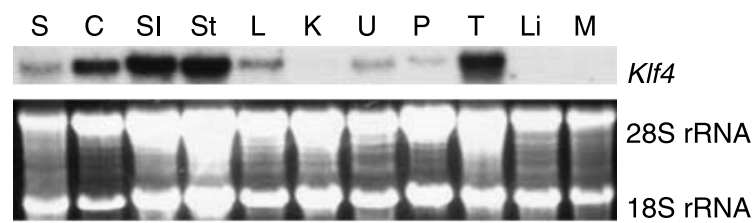

B

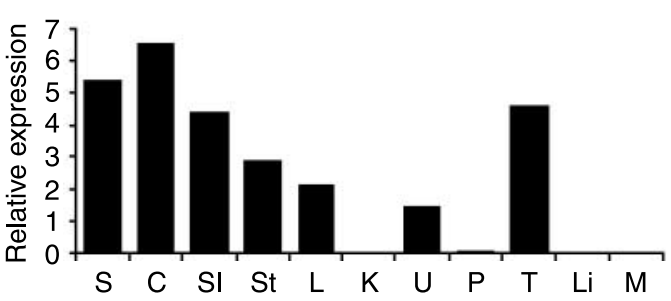

Figure 3 Klf4 mRNA expression in distinct mouse organs. (A) Northern blot analysis on total RNA ( $10 \mu \mathrm{g} /$ lane) isolated from different mouse tissues shows strong Klf4 expression in tissues of the gastrointestinal tract, but also in the lung and reproductive organs like the testis, the uterus, and the placenta. No signal can be detected in the kidney, the liver, or skeletal muscle. Northern blots were hybridized with a probe against the Klf4 open reading frame. (B) The graphic shows the ratio of Klf4 mRNA over the $28 \mathrm{~S}$ and $18 \mathrm{~S}$ rRNA of the appropriate formaldehyde gel. S, skin day 3; C, colon; SI, small intestine; St, stomach; L, lung; K, kidney; $U$, uterus; $\mathrm{P}$, placenta day $13 ; \mathrm{T}$, testis; $\mathrm{Li}$, liver; $\mathrm{M}$, skeletal muscle. 
(Fig. 4A) or cells without forskolin but with its solvent DMSO (Fig. 4B) exhibited only considerably weaker signals showing non-induced endogenous KLF4 expression. Remarkably, in addition to the increased signal intensity within the nucleus, there was also a clear cytoplasmic signal visible after forskolin induction possibly representing newly synthesized KLF4 protein before its transport into the nucleus.

\section{Very rapid induction of Klf4 $m R N A$}

After confirming the inducibility of KLF4 expression in TM4 cells by IF (Fig. 4), we wanted to investigate its expression kinetics in this Sertoli cell line in more detail. Since IF (Fig. 4) and northern blot analyses (data not shown; but provided as reviewer information) demonstrated that DMSO, the solvent of forskolin, had no obvious influence on Klf4 expression in TM4 cells, all subsequent studies were performed using DMSO-supplemented growth medium as a control. In order to analyze the kinetics of $K I f 4$ expression in response to forskolin, total RNA samples were collected from cells that have been treated with forskolin or DMSO for 10, 20, 30, 60, $90,120,150,180,210$, and $240 \mathrm{~min}$ and subjected to northern blot analyses (Fig. 5A, panels I and II).

Forskolin rapidly induced KIf4 expression. A signal above Klf4 basal levels in the corresponding DMSO control was already observed after 10 min of exposure.
Importantly, treatment caused a strong increase of $K / \mathrm{f} 4$ mRNA expression after $30 \mathrm{~min}$ and signals significantly peaked out around $90 \mathrm{~min}$. Thereafter, Klf4 levels declined quickly. After $240 \mathrm{~min}$, there was nearly no $K$ If4 detectable indicating a very transient increase in the KIf4 mRNA abundance upon activation of the PKA pathway (Fig. 5A and B).

In order to confirm that Klf4 expression is induced by forskolin-dependent activation of the PKA pathway, TM4 cells were treated simultaneously with forskolin and H89, a very potent PKA inhibitor. Total RNA was extracted after defined time points, and northern blot analyses demonstrated that forskolin-induced Klf4 expression could be completely repressed by $\mathrm{H} 89$ (Fig. 5A, panel III). Only Klf4 signals similar to DMSO control levels could be observed (Fig. 5A, panels II and III), indicating that KIf4 mRNA was specifically induced by forskolin activation of the PKA pathway.

\section{KLF4 protein is also rapidly induced by forskolin}

In addition to RNA analyses, we wanted to confirm KLF4 induction at the protein level. Western blot analyses were performed on the same individual cell cultures used for northern blotting (Fig. 5). Ten minutes after treatment, only a faint KLF4 protein signal could be detected, probably presenting endogenous, non-induced levels. However, $20 \mathrm{~min}$ after the addition of forskolin, KLF4
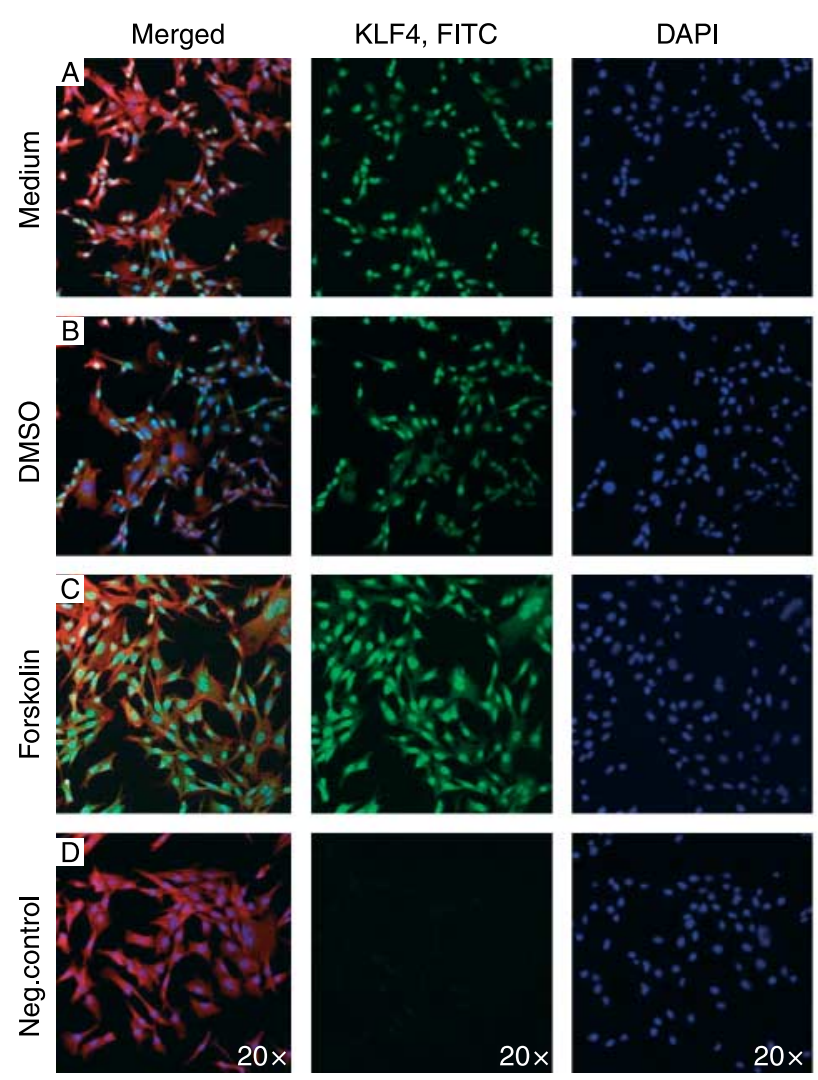

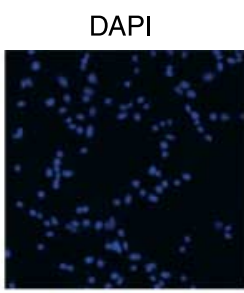

F-Actin,
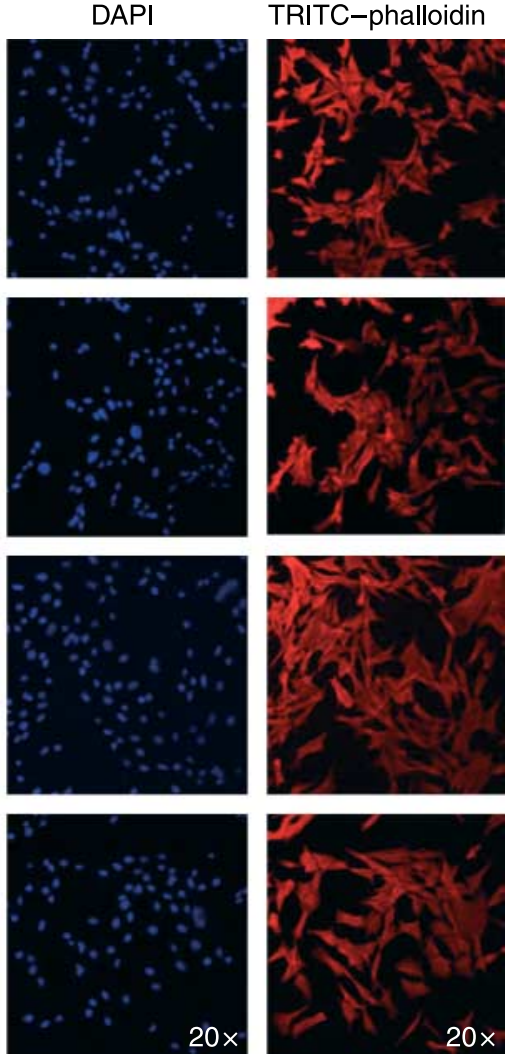

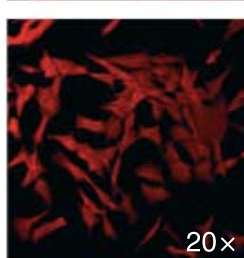

Figure 4 KLF4 immunofluorescence of forskolintreated TM4 cells. (A) A weak basal expression of KLF4 is observable in untreated TM4 cells (growth medium only) and in the DMSO control (B). Compared with the untreated $(\mathrm{A})$ and the DMSO control (B), KLF4 expression is clearly increased in TM4 cells after $1 \mathrm{~h}$ of forskolin treatment (C). The merged picture emphasizes the increase in KLF4 signal intensity (C). (D) The negative control shows forskolin-treated TM4 cells, but no KLF4 antibody was added. KLF4 was stained with a FITC-labeled secondary antibody, shown in green. Cell nuclei were DAPI-stained (blue). The cytoskeleton was visualized by F-actin staining using TRITC-labeled phalloidin (red). 
levels increased constantly and the highest protein concentrations were observed after 120 min of treatment. Thereafter, KLF4 protein levels declined rapidly and reached baseline levels already after $150 \mathrm{~min}$. $\beta$-Actin was used as a loading control (Fig. 6A and B).

\section{KIf4 is more rapidly induced than the inducible ICER}

As a biological and kinetic control for the induction of genes by cAMP in the TM4 Sertoli cell line, we analyzed the induction of the inducible ICER, which is expressed in different isoforms in the TM4 cells (Monaco et al. 1995). ICER was described as an early response gene after induction by forskolin, since its mRNA was first detectable after 60 min and reached highest levels around 120 and 240 min of treatment and declined thereafter (Monaco et al. 1995). We probed the same northern blot shown in Fig. 5A (panels I and II), with a probe specific for ICER and found a very similar pattern of ICER induction in our experiment compared with that published previously

A
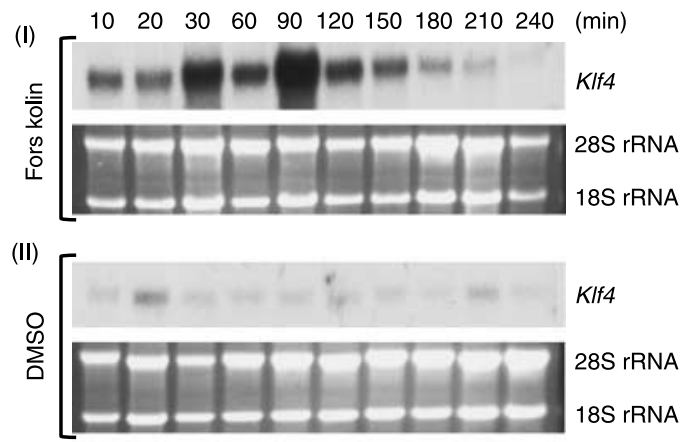

(III)

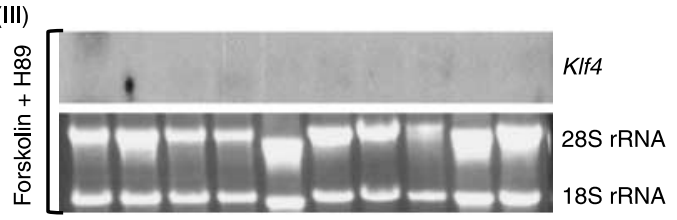

B

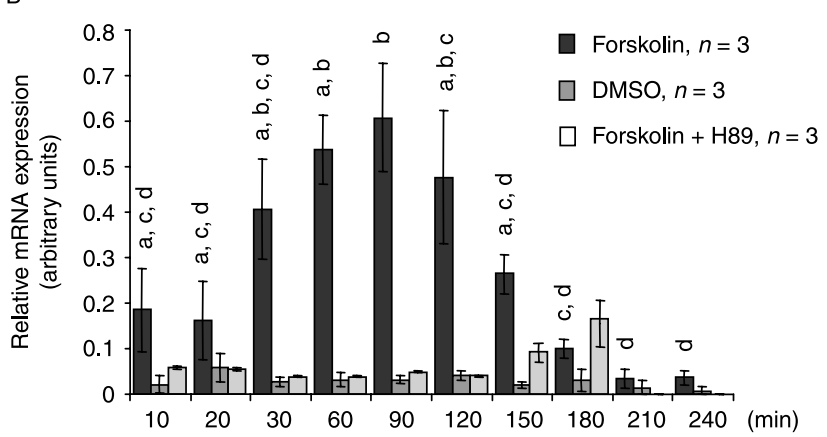

C

Forskolin

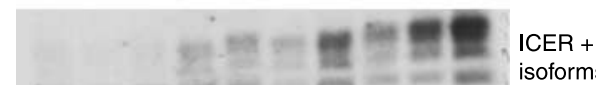

DMSO

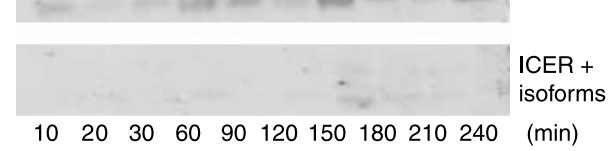

(Monaco et al. 1995): a weak induction was seen after 60 min of forskolin exposure as well as increased levels of ICER after $120 \mathrm{~min}$ (Fig. 5C, ICER + isoforms). Interestingly, the KIf4 gene responds much quicker to activation of the CAMP/PKA pathway in TM4 Sertoli cells than the early response gene ICER (Fig. 5A, panel I). Remarkably, the quick KIf4 response was very transient.

\section{Activation of the CAMP/PKA pathway has no influence on the cell cycle in TM4 Sertoli cells}

Since KLF4 expression is associated with cell cycle arrest (Garrett-Sinha et al. 1996, Shields et al. 1996) and since Klf4 is quickly and strongly induced by forskolin, we investigated whether activation of the cAMP/PKA pathway in TM4 cells influenced cell cycle progression. Using fluorescence-activated cell sorting (FACS) of propidium iodide-stained cells, we analyzed synchronized TM4 cells treated with i) forskolin in $0.1 \%$ DMSO in growth medium or ii) the solvent $(0.1 \%$ DMSO) in growth medium alone or iii) untreated cells (growth medium only). Cells were harvested after $0,1,3,6,12$, and $24 \mathrm{~h}$ and analyzed for cell cycle progression by DNA content. Interestingly, we found no differences between the cultures indicating that activation of the CAMP/PKA pathway in TM4 cells and subsequent upregulation of KLF4 (and other genes/proteins) did not affect progression through the cell cycle in this experimental setup (Fig. 7). These results were confirmed by two additional independent experiments.

Figure 5 Rapid induction of Klf4 expression in TM4 cells after forskolin exposure. (A) Northern blot analyses on TM4 cell total RNA extracts (10 $\mu \mathrm{g} /$ lane) show that $\mathrm{Klf4}$ expression is rapidly induced by forskolin (panel I). Only 10 min after treatment, there is a distinguishable and after 30 min a strong increase in Klf4 signal intensity compared with control conditions (TM4 cells cultured in growth medium + DMSO, panel II). Highest Klf4 mRNA levels could be detected after 90 min of forskolin exposure, whereas the DMSO control exhibits constantly weak signals. Panel III shows the repression of forskolin-induced KIf4 expression by the PKA inhibitor H89 (forskolin + H89). The corresponding gel photos below indicate RNA loading. (B) Relative KIf4 mRNA expression shown as the ratio of Klf4 mRNA over $28 \mathrm{~S}$ rRNA and $18 \mathrm{~S}$ rRNA of the corresponding formaldehyde gel. The graphic demonstrates the quick response of Klf4 expression to forskolin compared with DMSO (control) and to cells that have been simultaneously treated with forskolin and the PKA inhibitor H89. Results are depicted as mean \pm s.E.M. N indicates the number of independent experiments. Bars labeled with different letters depict statistical significant differences $(P<0.05$; for all, except 90 vs 180,210 , or 240 min respectively, where $P<0.01$ ). (C) In order to arrange KIf4 induction chronologically, we analyzed the expression of ICER (inducible cAMP early repressor). ICER is classified as an immediate early cAMP response gene. ICER mRNA levels increase $60 \mathrm{~min}$ after forskolin exposure and peak $240 \mathrm{~min}$ after treatment. Notably, compared with ICER, KIf4 expression is clearly induced within the first $30 \mathrm{~min}$ and reaches its maximal concentration after $90 \mathrm{~min}$. Klf4 thus responds much quicker to the activation of the cAMP/PKA pathway than ICER. DMSO-treated control TM4 cells showed almost no ICER signal. 
A

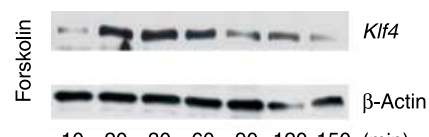

$10 \quad 20 \quad 30 \quad 60 \quad 90 \quad 120150$ (min)

B

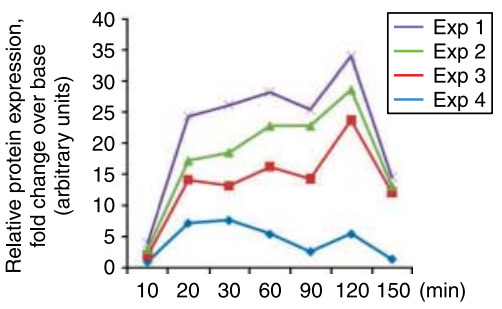

Figure 6 Induction of KLF4 protein expression in TM4 cells after forskolin treatment. (A) Western blot analyses of KLF4 expression on total TM4 cell protein extracts after stimulation with forskolin (30 $\mu \mathrm{g} /$ lane). $\beta$-Actin served as a loading control and was used for normalization purpose. (B) KLF4 signals from proteins isolated 10 min after forskolin stimulation match the endogenous (non-stimulated) protein levels and served as base - the corresponding ratio of KLF4 to $\beta$-actin was defined as 1 . Fold change indicates the ratio of KLF4 protein normalized to $\beta$-actin after time of forskolin treatment over the base. Four independent experiments are depicted. An increase of the KLF4 expression is observable $20 \mathrm{~min}$ after forskolin exposure, and KLF4 protein levels peak at $120 \mathrm{~min}$. Thereafter, the KLF4 signal intensity declines quickly. The $y$-axis indicates the fold change of relative KLF4 protein expression over the base in arbitrary units and the $x$-axis shows the timeline of forskolin exposure in minutes.

\section{Discussion}

Lack of KLF4 in the epidermis, the epithelium of the stomach, and colon or the epithelium of the tongue has tremendously impairing effects on the differentiation and/or function of these tissues, as has been proven in vivo by Klf4 gene inactivation studies in mice (Segre et al. 1999, Katz et al. 2002, 2005, Swamynathan et al. 2007). Since deletion of Klf4 had also significant effects on leukocyte development and function (Feinberg et al. 2007, Klaewsongkram et al. 2007) and on maturation and maintenance of the epithelial ocular surface (Swamynathan et al. 2007), it is evident that KLF4 is an important player during the differentiation of many adult cell types. We have shown in this work that KLF4 is expressed in several tissues constituting the adult male and female reproductive tract. Therefore, it is conceivable and likely that KLF4 might also be an important factor for the development and function of the reproductive tract in both sexes in mice. Future studies applying cell type-specific deletion of KIf4 in the respective cell types will reveal the functions of KLF4 during mouse reproduction. Especially, the strong KLF4 expression in the uterine epithelium, the vagina, and in the epithelia of the male excretory ducts suggests an important function in the respective cell types. However, we have recently shown that deletion of KIf4 in spermatids did not impair spermiogenesis and that the male mutant mice were fertile (Godmann et al. 2009b). This finding may suggest that KLF activity is dispensable for spermiogenesis or alternatively that the lack of KLF4 can be compensated by other KLF family members as has already been shown in mouse embryonic stem cells (Jiang et al. 2008). Therefore, further studies also will have to elucidate whether other KLF family members, e.g. KLF2 and KLF5, are co-expressed together with KLF4 in those cells studied in the present work.

The CREM gene isoform ICER (inducible cAMP early repressor) has been described as an immediate early response gene in TM4 Sertoli (Monaco et al. 1995) and in WEHI7.2 thymoma cells (Mao et al. 1998). In both cell lines, CAMP-induced expression of ICER exhibited almost identical kinetics with peak levels around $3 \mathrm{~h}$ after induction. Interestingly, as shown in this work, KIf4 gene expression is significantly earlier induced after PKA activation, i.e. a strong induction of Klf4 expression could be detected after $30 \mathrm{~min}$, peaking out at $90 \mathrm{~min}$. Moreover, the mRNA as well as the protein levels also decreased very quickly after the forskolin stimulus. According to our knowledge, this makes KIf4 one of the fastest responders to CAMP described so far. An intensive literature search revealed only a limited number of mRNAs and/or proteins with similar induction characteristics after PKA activation. For instance, the transcription factor Egr1 exhibits comparable induction
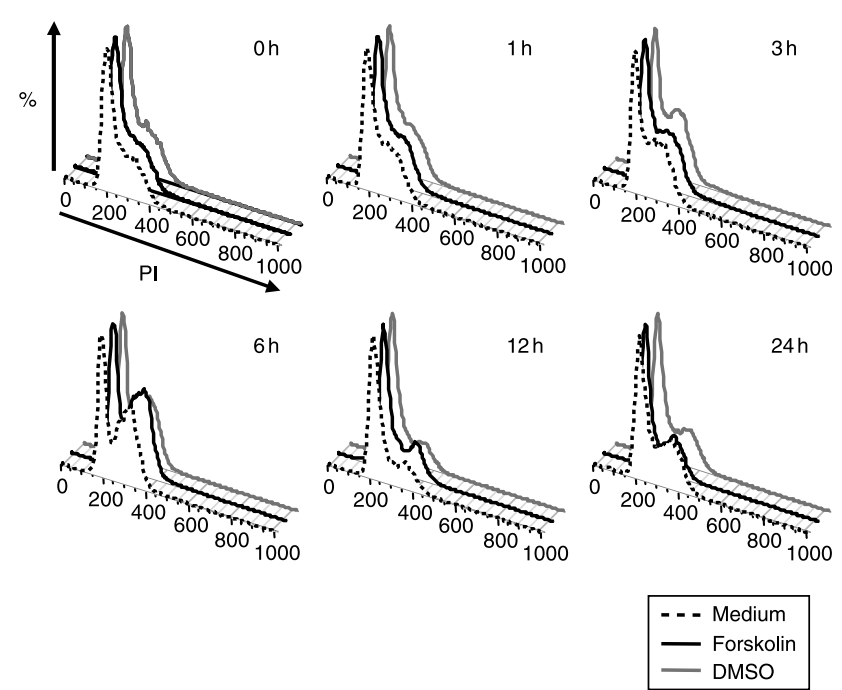

Figure 7 Measurement of the TM4 cell DNA content after forskolin stimulation and subsequent KIf4 induction. The cell cycle status of synchronized and forskolin or DMSO-treated or untreated TM4 cells was determined according to the DNA content of the cells by propidium iodide staining $(\mathrm{PI})$ and fluorescence-activated cell sorting (FACS) analysis. Three-dimensional diagrams show cell cycle progression over a period of $24 \mathrm{~h}$ of untreated (only medium, black dotted line), forskolin-stimulated TM4 cells (black line) and cells treated with DMSO (grey line). $Y$-axis, relative cell number; $X$-axis, relative DNA content indicated by propidium iodide staining. $G_{0} / G_{1}$ peaks at 200 and $\mathrm{G}_{2} / \mathrm{M}$ at 400 . 
kinetics (Tai et al. 2001). After forskolin stimulation of PC12 cells, EGR1 protein was strongly induced after $30 \mathrm{~min}$, peaked after $45 \mathrm{~min}$, and was back to the unstimulated level after $90 \mathrm{~min}$. Such findings are in agreement with the kinetics of an immediate early gene. However, they are in part in contrast to ICER since ICER protein was much more stable than KLF4 and EGR1, and a decline of ICER protein was detectable only after $36 \mathrm{~h}$ (Monaco et al. 1995). Compared with ICER, the transient induction of KLF4 protein in TM4 cells can execute only short-term primary effects as has been postulated earlier for immediate early genes (Herschman 1991).

There were two genes described with similar induction kinetics on the mRNA level after serum stimulation of BALB/c-3T3 cells, i.e. c-Fos and c-Myc (Greenberg et al. 1986). C-Fos was strongly induced after $15 \mathrm{~min}$ and almost back to the unstimulated level after $60 \mathrm{~min}$. $C-M y c$ showed slightly increased mRNA levels after $30 \mathrm{~min}$ and remained high for at least $4 \mathrm{~h}$. This has been confirmed by others (Lau \& Nathans 1987). Moreover, this latter report described five additional immediate early mRNAs in BALB/c-3T3 cells after serum stimulation of quiescent cells. Two of these not further characterized mRNAs were also clearly induced after $10 \mathrm{~min}$ after stimulation. Additionally, in PC12 pheochromocytoma cells, c-Fos proto-oncogene was rapidly induced within $5 \mathrm{~min}$ after the addition of nerve growth factor (Greenberg et al. 1985). Thus, Klf4 belongs to a small group of genes responding really immediately, i.e. within $<15 \mathrm{~min}$, to activation of signal transduction cascades.

Interestingly, KIf4 has also been described as an immediate early gene in recent papers basically confirming the induction kinetics of Klf4 demonstrated in the present study (Granberg et al. 2006, Liu et al. 2006, Maallem et al. 2008, Dijkmans et al. 2009). However, only the study by Dijkmans et al. (2009) measured the induction already after $15 \mathrm{~min}$, while the other studies measured gene induction first after 45 (Maallem et al. 2008) or 60 (Granberg et al. 2006) min respectively. The inductive stimuli were nerve growth factor (Dijkmans et al. 2009), adenoviral infection (Granberg et al. 2006), and systemic hypertonicity in rats (Maallem et al. 2008). Since nerve growth factor has pleiotropic effects (Dijkmans et al. 2009 and references therein), in neither study the particular biochemical signal transduction pathways resulting in Klf4 induction have been determined. In contrast, in the present study, we could clearly show that PKA signaling was causative for the induction of KIf4 mRNA (see also below).

During recent years, it became evident that not all effects of increased intracellular cAMP can be attributed to PKA action (Richards 2001, Walker \& Cheng 2005). For example, the kinases protein kinase B, phosphoinositidyl-3-kinase/PDK1, and SGK also appear to be responsive to increased cAMP levels. Previous studies on $\mathrm{FSH}$-inducible genes did not reveal the identity of the intracellular signal transduction pathway, which led to the induction of Klf4. In this work, we could show that indeed the cAMP/PKA pathway is responsible for KIf4 induction. While forskolin is an activator of the adenylyl cyclase, which can activate several intracellular signaling pathways through increased cAMP levels, the protein kinase inhibitor H89, which was used in this study and completely blocked KIf4 induction, does not inhibit any of these kinases found to be activated by increased cAMP levels except the PKA. The fact that KIf4 induction is abolished by the protein kinase inhibitor $\mathrm{H} 89$ shows that indeed the CAMP/PKA pathway is responsible for Klf4 gene induction.

There are earlier studies that demonstrate the inducibility of Klf4 mRNA in primary Sertoli cells upon an FSH stimulus (Hamil \& Hall 1994, McLean et al. 2002, Sadate-Ngatchou et al. 2004). Nevertheless, the earliest time points investigated in these studies on the Sertoli cell were 2 and $2.5 \mathrm{~h}$ after stimulation respectively, thus not covering the time range typical of an immediate early response gene (Herschman 1991). Moreover, these studies did not investigate KLF4 protein induction. It is still unclear how this very rapid gene induction is achieved. However, we propose two models. The first model involves the transcription factor CREB, which can be phosphorylated by the PKA (Sassone-Corsi 1998). Activated CREB could bind to the KIf4 gene promoter and activate it immediately after activation of the cAMP/PKA signal transduction pathway. Indeed, a conserved $\mathrm{CRE}$, the binding site of the transcription factors CREB and CRE modulator in CAMP-responsive genes, has been found in the KIf4 gene promoter (Zhang et al. 2005). However, this CRE is much further upstream $(\sim 3 \mathrm{~kb})$ from the transcription start site than most CREs found to be functional. Therefore, it remains to be proven whether this CRE is important for the rapid induction of KIf4. Another model for the rapid KIf4 gene induction is an auto-regulatory mechanism. The KLF4 protein has four probable PKA phosphorylation sites (Blom et al. 1999). Since it has been shown that KLF4 can activate its own promoter (Mahatan et al. 1999) and since even in the uninduced state there are basal levels of KLF4 protein present (see Fig. 4), it is conceivable that KLF4 itself is the primary target of the PKA and binds upon activation by the PKA to its own promoter. A third possibility is that the KIf4 gene promoter can primarily be activated by an as yet unknown PKA-activated transcription factor.

Interestingly, KLF4 protein levels decline very quickly after peaking at $120 \mathrm{~min}$. Although Klf4 mRNA signals are still moderate after 150 min of forskolin exposure, the protein concentrations reach a level that is similar to what is observed initially after $10 \mathrm{~min}$ of treatment and which probably represents endogenous KLF4 basal expression. Owing to the fact that this behavior was consistently reproduced, it is highly likely that the KLF4 protein is less stable and rapidly degraded in TM4 cells. Recent findings in the literature support this 
explanation: i) Chen et al. (2005) demonstrated that KLF4 exhibited a half-life of $\sim 120 \mathrm{~min}$ and that it was rapidly degraded by the ubiquitin-proteasome complex. Furthermore, ii) KLF4 contains a PEST domain (Shields et al. 1996), which is characteristic of proteins with very short half-lives of $<2 \mathrm{~h}$ (Rogers et al. 1986, Babon et al. 2006).

Moreover, we have previously shown that KIf4 mRNA contains some sequence motifs in its 3'-UTR, which strongly resemble or perfectly match binding sites for proteins repressing translation (Godmann et al. 2005). Thus, it is conceivable that translation of the KIf4 mRNA is also strictly controlled in TM4 cells so that KLF4 protein levels can decline even before the corresponding mRNA has been degraded. However, it is beyond the scope of the present study to unravel the molecular mechanisms responsible for the KLF4 protein degradation.

KLF4 has been implicated in cell cycle regulation by controlling the $\mathrm{G}_{1} / \mathrm{S}$ and the $\mathrm{G}_{2} / \mathrm{M}$ cell cycle checkpoints (Shields et al. 1996, Yoon \& Yang 2004). Upregulation of KLF4 caused an arrest of cell cycle progression. Therefore, we were interested in whether forskolin-induced upregulation of KLF4 in the TM4 cell line would have an effect on cell cycle progression of these cells. Interestingly, we found no such effect, neither a total block nor a delay. This was somewhat surprising since other systems including in vitro cell culture systems showed such a KLF4-mediated cell cycle block, for instance by down-regulating the M-phase cyclin B (Yoon \& Yang 2004). An explanation for the finding in the present study could be that the induction of KIf4 expression in the TM4 cells was too transient to mediate long-term effects on the cell cycle. Another possibility is that the immortal TM4 cell line overrides the normal cellular response to KLF4 induction by its aberrant cellular program that enables the cells to grow indefinitely in vitro.

Furthermore, it is also possible that KLF4 is not involved in cell cycle regulation in Sertoli cells, since our in vivo studies demonstrated that the lack of KLF4 in Sertoli cells caused a functional delay in Sertoli cell differentiation but did not affect their proliferative behavior (Godmann et al. 2008).

In summary, we show for the first time expression of KLF4 in distinct cell types of the male and female murine reproductive tract including the epididymis, the vas deferens, the penis, the uterus, and the vagina. Keeping the relevance of KLF4 in many different mouse cell types in mind, the strong expression of KLF4 in several cell types of the reproductive tract may suggest an important role of KLF4 also during reproductive functions in mice. In TM4 Sertoli cells, KIf4 mRNA and protein are very rapidly and specifically induced by the CAMP/PKA signal transduction pathway. Moreover, the induction was very transient, classifying Klf4 as an immediate early gene in response to PKA activation in TM4 Sertoli cells.

\section{Materials and Methods}

\section{Immunohistochemistry}

Bouin's-fixed and paraffin-embedded mouse tissue specimens were sectioned at $6 \mu \mathrm{m}$. Sections were rehydrated and an antigen retrieval step was performed by microwaving the sections in $0.01 \mathrm{M}$ sodium citrate buffer ( $\mathrm{pH}$ 6.0) for $10 \mathrm{~min}$. Unspecific binding of the first antibody was blocked by a $60-\mathrm{min}$ incubation step in $5 \%(\mathrm{w} / \mathrm{v}) \mathrm{BSA}$ in $0.05 \mathrm{~mol} / \mathrm{l}$ Tris- $\mathrm{HCl}, 0.15 \mathrm{~mol} / \mathrm{l} \mathrm{NaCl}, \mathrm{pH} 7.6$ (TBS). A rabbit polyclonal antibody raised against the $180 \mathrm{~N}$-terminal amino acids of KLF4 of human origin (SC-20691; Santa Cruz Biotechnology) was used at a 1:600 dilution in 5\% BSA in TBS. Additionally, a KLF4 affinity-purified polyclonal antibody directed against recombinant full-length mouse KLF4 (AF3158; R\&D Systems) was used in a 1:50 or 1:100 dilution. All incubation steps were done in a humid chamber and incubations with the primary antibodies were performed overnight at $4{ }^{\circ} \mathrm{C}$. DakoCytomation Universal LSAB 2 System-AP (K0674) including biotinylated secondary antibody polymer and alkaline phosphatase (AP)-conjugated streptavidin or DakoCytomation Universal LSAB 2 System-HRP (K0672) including biotinylated secondary antibody polymer and HRP was employed for detection of bound primary antibody. Fuchsin (K0624) chromogen or 3-3' diaminobenzidine was used as a substrate for the AP or HRP respectively. Mayer's hematoxylin served as counterstain. Control stains were carried out using normal rabbit or goat sera respectively, instead of the primary antibody. Tissue samples from two to seven different animals were analyzed.

\section{Cell culture}

TM4 cell culture

TM4 cells (kindly provided by Dr Thomas Walther, Berlin) were cultured in growth medium consisting of 46\% DMEM (with $4500 \mathrm{mg} / \mathrm{l}$ glucose, with pyridoxine $\mathrm{HCl}$, without sodium pyruvate), 46\% Ham's F12 (with $10 \mathrm{mg} / \mathrm{l}$ phenol red, with $1.176 \mathrm{~g} / \mathrm{N} \mathrm{NaHCO}_{3}$, without L-glutamine), 6.5\% FCS, $15 \mathrm{mM}$ HEPES, 25000 Units penicillin per $500 \mathrm{ml}$, and $25 \mathrm{mg}$ streptomycin per $500 \mathrm{ml}$.

\section{Stimulation and inhibition of the adenylyl cyclase pathway in TM4 cells}

TM4 cells $\left(5 \times 10^{5}\right)$ were grown on cell culture dishes (diameter: $10 \mathrm{~cm}$ ) for $24 \mathrm{~h}$. Afterwards, cells were treated with $10 \mu \mathrm{M}$ forskolin (Sigma-Aldrich) in growth medium or $10 \mu \mathrm{M}$ forskolin and $75 \mu \mathrm{M}$ H89 ( $\mathrm{N}$-[2-p-bromocinnamylamino)ethyl]-5-isoquinoline-sulfonamide $2 \mathrm{HCl}$; Biosource, Camarillo, CA, USA) in growth medium or $0.26 \%$ DMSO in growth medium or growth medium alone. RNA was isolated after 10, 20, 30, 60, $90,120,180$, and 240 min incubation time.

\section{Synchronization of TM4 cells}

TM4 cells $\left(5 \times 10^{4}\right.$ cells/well) were grown on six-well plates for $24 \mathrm{~h}$, washed twice with Moscona's buffer containing $13.6 \mathrm{mM}$ $\mathrm{NaCl}, 4 \mathrm{mM} \mathrm{KCl}, 12 \mathrm{mM} \mathrm{NaHCO}, 10 \mathrm{mM}$ D-glucose, 


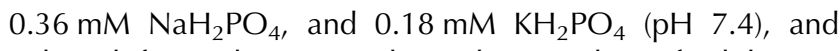
cultured for $24 \mathrm{~h}$ in growth medium without fetal bovine serum. Then, cells were treated with $10 \mu \mathrm{M}$ forskolin (SigmaAldrich), which were dissolved in DMSO (final concentration in the medium $0.1 \%$ ), in growth medium, $0.1 \%$ DMSO in growth medium, or growth medium alone. The DNA content of the stimulated TM4 cells was analyzed as described below.

\section{Immunofluorescence}

TM4 cells $\left(2 \times 10^{4}\right)$ were grown on chamber slides $\left(4.2 \mathrm{~cm}^{2} /\right.$ well $)$ overnight and then stimulated with $10 \mu \mathrm{M}$ forskolin dissolved in DMSO for $1 \mathrm{~h}$ under cell culture conditions as described above. Incubation of TM4 cells with $0.1 \%$ DMSO in growth medium or growth medium alone served as controls. After stimulation, cells were rinsed twice with Moscona's buffer, fixed with $4 \%$ paraformaldehyde/Moscona's buffer for $30 \mathrm{~min}$, and permeabilized with $0.05 \%$ Triton in $\mathrm{dd}_{2} \mathrm{O}$ for $5 \mathrm{~min}$, both at room temperature. Cells were rinsed twice with Moscona's buffer. Non-specific binding sites were blocked with $0.5 \%$ BSA in Moscona's buffer for $1 \mathrm{~h}$ at $4{ }^{\circ} \mathrm{C}$. Then, cells were incubated with an anti-KLF4 antibody (H180, sc-20691, Santa Cruz Biotechnology, 1:500 in 0.5\% BSA/Moscona's buffer) overnight at $4{ }^{\circ} \mathrm{C}$. Next day, TM4 cells were washed thrice in $0.5 \%$ BSA/Moscona's buffer and incubated with a mixture consisting of secondary antibody (Alexa Flour 488, A11008, Molecular Probes/MoBiTec, Göttingen, Germany; 1:200 in 0.5\% BSA/Moscona's buffer) and $5 \mu \mathrm{g} / 500 \mu \mathrm{l}(7.66 \mu \mathrm{M})$ tetramethylrhodamine isothiocyanate-conjugated phalloidin (Sigma) for F-actin staining, for $1 \mathrm{~h}$ at room temperature in the dark. After washing, cell nuclei were DAPI stained (1:200 in 0.5\% BSA/Moscona's buffer; $15 \mathrm{~min}$ at room temperature in the dark), cells were rinsed once with $0.5 \%$ BSA/Moscona's buffer, twice with $d_{d} \mathrm{H}_{2} \mathrm{O}$, and mounted with DAKO Faramount aqueous medium (DAKO Cytomation, Hamburg, Germany).

Confocal microscopy was performed using a Zeiss Axiovert $100 \mathrm{M}$ microscope attached to a confocal laser scanning microscopy system (model LSM 510; objective: PlanApochromat $20 \times 0.75$; Carl Zeiss, Jena, Germany) as described previously (Heneweer et al. 2002). As excitation sources, an argon laser with output at $488 \mathrm{~nm}$, a helium-neon laser with output at $543 \mathrm{~nm}$, and an Enterprise laser with output at $364 \mathrm{~nm}$ were available. To improve the signal-to-noise ratio, each slice was scanned eight times followed by averaging.

\section{RNA isolation and northern blotting}

Total RNA was extracted from different mouse tissues and the TM4 Sertoli cell line using peqGOLD-TriFast (peqLab Biotechnology $\mathrm{GmbH}$, Erlangen, Germany) following the manufacturer's instructions. Performing northern blot analysis, total RNA was additionally purified using the RNeasy Mini Kit (Qiagen). Ten (Fig. 3) or five (Fig. 5) micrograms respectively of purified total RNA per sample were electrophoresed in $1 \%$ agarose/3-( $N$-morpholino)propanesulfonic acid/formaldehyde gels, blotted onto nylon membranes (Amersham Pharmacia), and cross-linked by u.v. irradiation. Filters were prehybridized at $68{ }^{\circ} \mathrm{C}$ for $60 \mathrm{~min}$ in ExpressHyb buffer (BD Biosciences Clontech). $\alpha-\left[{ }^{32} \mathrm{P}\right]-\mathrm{dCTP}$ was incorporated into the probe using the High Prime solution from Roche Molecular Biochemicals. Hybridizations were performed at $68{ }^{\circ} \mathrm{C}$ for $16 \mathrm{~h}$. Membranes were washed thrice for $20 \mathrm{~min}$ each time in $2 \times \mathrm{SSC} / 0.1 \%$ SDS at room temperature and twice for $30 \mathrm{~min}$ each time in $0.1 \times \mathrm{SSC} / 0.1 \%$ SDS at $50{ }^{\circ} \mathrm{C}$. The membranes were exposed to an X-ray film (Kodak) for $16-72 \mathrm{~h}$ at $-80^{\circ} \mathrm{C}$ in an exposure cassette with intensifier screens. To generate the Klf4 open reading frame probe, the entire coding region was amplified from mouse testis cDNA by PCR using the following primer combinations: Ex 1 -fw $5^{\prime}$-cct tct ggg ccc cca cat ta-3'; Ex5-re 5'-gtc aca tcc act acg tgg gat-3'. The ICER probe was amplified using: mmICER-fw1 gac tgt ggt acg gCc aat aag; mmDBD2-ICER-re1 gtt ctg aac ttc cag cac tgc. PCR products were subcloned into the pCRII vector (Invitrogen) and sequenced. Ten micrograms of each plasmid DNA were digested with 20 Units of EcoRI, separated by electrophoresis and gel purified (MinElute, Qiagen). Approximately, $100 \mathrm{ng}$ of each probe were radiolabeled with $\alpha-\left[{ }^{32} \mathrm{P}\right]-\mathrm{dCTP}$ (Hartmann Analytic, Braunschweig, Germany) using High Prime Solution (Roche Molecular Biochemicals. Prior to rehybridization with a different probe, northern blots were dehybridized by boiling the membranes in $0.1 \times \mathrm{SSC} /$ $1 \%$ SDS for $15 \mathrm{~min}$.

\section{Immunoblotting}

After isolation of total RNA from TM4 cells, proteins of the same individual cultures were also extracted using the peqGOLD-TriFast system (peqLab Biotechnology) following the manufacturer's instructions. Total protein was quantified using Micro BCA Protein Assay Reagent Kit from Pierce Biotechnology/Perbio Science (Bonn, Germany). Protein extracts $(30 \mu \mathrm{g} /$ lane) from TM4 cells were separated by SDS-PAGE (10\% SDS-PAGE) and transferred to a nitrocellulose membrane. The membranes were blocked in 5\% non-fat dry milk powder/PBS/0.1\% Tween 20 for $1 \mathrm{~h}$ at room temperature. Then, the anti-KLF4 primary antibody (Rowland et al. 2005, H180, sc-20691, Santa Cruz Biotechnology, Heidelberg, Germany) was diluted $1: 4000$ in $5 \%$ milk powder/PBS/0.1\% Tween 20, and applied to the membranes, which were incubated overnight at $4{ }^{\circ} \mathrm{C}$. After washing, the protein-antibody complexes were detected with a HRP-conjugated secondary antibody (Goat anti-Rabbit IgG-HRP, Santa Cruz Biotechnology), diluted $1: 20000$ in $5 \%$ milk powder/PBS/ $0.1 \%$ Tween 20 for $1 \mathrm{~h}$ at room temperature using the ECL plus detection system (GE Healthcare, Uppsala, Sweden). Total protein extracts from mouse skin and stomach were used as a positive control and subjected to western blot analyses in order to evaluate the functionality of the KLF4 antibody from R\&D Systems (AF3158). The primary antibody was used in a 1:1000 dilution, and the secondary antibody (Santa Cruz SC-2922) was used in a 1:5000 dilution.

\section{DNA content analysis}

To explore a potential role of KLF4 in cell cycle progression of TM4 cells, $5 \times 10^{4}$ cells/well were grown on cell culture dishes 
(diameter: $3.5 \mathrm{~cm}$ ) and treated with $10 \mu \mathrm{M}$ forskolin in $0.1 \%$ DMSO in growth medium, $0.1 \%$ DMSO in growth medium, or growth medium alone after synchronization as described above. Cells were harvested after $0,1,3,6,12$, and $24 \mathrm{~h}$ of stimulation, washed once in PBS, and fixed and permeabilized in $100 \mu \mathrm{l}$ Cytofix/Cytoperm solution (Becton Dickinson, San Jose, CA, USA) overnight at $4{ }^{\circ} \mathrm{C}$. The fixation/permeabilization solution was removed by the addition of $1 \mathrm{ml}$ Perm/Wash buffer and centrifuged at $173 \boldsymbol{g}$ in a Heraeus Megafuge for $5 \mathrm{~min}$ at room temperature. After the addition of $0.25 \mathrm{mg} / \mathrm{ml}$ RNase A and $20 \mu \mathrm{g} / \mathrm{ml}$ propidium iodide in PBS, the cell suspension was incubated in the dark for $30 \mathrm{~min}$ at $4{ }^{\circ} \mathrm{C}$. Cell cycle analysis was done by using FACS Calibur flow cytometer (Becton Dickinson). The data were collected with Cell Quest and analyzed using Flowjo Software (Becton Dickinson).

\section{Analyses of relative $m R N A$ expression and protein levels}

The analyses of relative mRNA expression (northern blotting) and relative protein levels (immunoblotting) were done using the AlphaDigiDoc analysis system (Alpha Innotech Corporation, San Leandro, CA, USA). The KIf4 mRNA signals were normalized to the corresponding $28 \mathrm{~S}$ rRNA and 18S rRNA (formaldehyde gel), and the KLF4 protein was normalized to $\beta$-actin (SC-1616, Santa Cruz). If not otherwise indicated, each experiment was repeated a minimum of three times. All values are expressed as means \pm s.E.M. To detect significant effects of forskolin treatment, a one-way ANOVA was performed and to identify differences between means, a Student-Newman-Keuls test means comparison was applied.

\section{Declaration of interest}

The authors declare that there is no conflict of interest that could be perceived as prejudicing the impartiality of the research reported.

\section{Funding}

This work was supported by a grant from the Deutsche Forschungsgemeinschaft (DFG) to R Behr (Be2296/4).

\section{Acknowledgements}

We appreciate the support of Dr Renate Renkawitz-Pohl, Dr Hans-Werner Denker, and Dr Trevor Cooper. The technical assistance of Isabell Kromberg, Marion Niebeling, Nicole Umland, and Vera Liebau is gratefully acknowledged.

\section{References}

Babon JJ, McManus EJ, Yao S, DeSouza DP, Mielke LA, Sprigg NS, Willson TA, Hilton DJ, Nicola NA, Baca M et al. 2006 The structure of SOCS3 reveals the basis of the extended $\mathrm{SH} 2$ domain function and identifies an unstructured insertion that regulates stability. Molecular Cell 22 205-216.
Behr R \& Kaestner KH 2002 Developmental and cell type-specific expression of the zinc finger transcription factor Kruppel-like factor 4 (Klf4) in postnatal mouse testis. Mechanisms of Development 115 167-169.

Behr R, Deller C, Godmann M, Muller T, Bergmann M, Ivell R \& Steger K 2007 Kruppel-like factor 4 expression in normal and pathological human testes. Molecular Human Reproduction 13 815-820.

Blom N, Gammeltoft S \& Brunak S 1999 Sequence and structure-based prediction of eukaryotic protein phosphorylation sites. Journal of Molecular Biology 294 1351-1362.

Chen X, Whitney EM, Gao SY \& Yang VW 2003 Transcriptional profiling of Kruppel-like factor 4 reveals a function in cell cycle regulation and epithelial differentiation. Journal of Molecular Biology 326 665-677.

Chen ZY, Wang X, Zhou Y, Offner G \& Tseng CC 2005 Destabilization of Kruppel-like factor 4 protein in response to serum stimulation involves the ubiquitin-proteasome pathway. Cancer Research 65 10394-10400.

Dang DT, Bachman KE, Mahatan CS, Dang LH, Giardiello FM \& Yang VW 2000 Decreased expression of the gut-enriched Kruppel-like factor gene in intestinal adenomas of multiple intestinal neoplasia mice and in colonic adenomas of familial adenomatous polyposis patients. FEBS Letters 476 203-207.

Dang DT, Chen X, Feng J, Torbenson M, Dang LH \& Yang VW 2003 Overexpression of Kruppel-like factor 4 in the human colon cancer cell line RKO leads to reduced tumorigenecity. Oncogene 22 3424-3430.

Dijkmans TF, van Hooijdonk LW, Schouten TG, Kamphorst JT, Fitzsimons CP \& Vreugdenhil E 2009 Identification of new nerve growth factor-responsive immediate-early genes. Brain Research 1249 19-33.

Don J \& Stelzer G 2002 The expanding family of CREB/CREM transcription factors that are involved with spermatogenesis. Molecular and Cellular Endocrinology 187 115-124.

Feinberg MW, Wara AK, Cao Z, Lebedeva MA, Rosenbauer F, Iwasaki H, Hirai H, Katz JP, Haspel RL, Gray S et al. 2007 The Kruppel-like factor KLF4 is a critical regulator of monocyte differentiation. EMBO Journal 26 4138-4148.

Garrett-Sinha LA, Eberspaecher H, Seldin MF \& de Crombrugghe B 1996 A gene for a novel zinc-finger protein expressed in differentiated epithelial cells and transiently in certain mesenchymal cells. Journal of Biological Chemistry 271 31384-31390.

Ghaleb AM, McConnell BB, Nandan MO, Katz JP, Kaestner KH \& Yang VW 2007 Haploinsufficiency of Kruppel-like factor 4 promotes adenomatous polyposis coli dependent intestinal tumorigenesis. Cancer Research $\mathbf{6 7}$ 7147-7154.

Godmann M, Kromberg I, Mayer J \& Behr R 2005 The mouse Kruppel-like factor 4 (Klf4) gene: four functional polyadenylation sites which are used in a cell-specific manner as revealed by testicular transcript analysis and multiple processed pseudogenes. Gene 361 149-156.

Godmann M, Katz JP, Guillou F, Simoni M, Kaestner KH \& Behr R 2008 Kruppel-like factor 4 is involved in functional differentiation of testicular Sertoli cells. Developmental Biology 315 552-566.

Godmann M, Gashaw I, Eildermann K, Schweyer S, Bergmann M, Skotheim RI \& Behr R 2009a The pluripotency transcription factor Kruppel-like factor 4 is strongly expressed in intratubular germ cell neoplasia unclassified and seminoma. Molecular Human Reproduction 15 479-488.

Godmann M, Gashaw I, Katz JP, Nagy A, Kaestner KH \& Behr R 2009b Kruppel-like factor 4, a "pluripotency transcription factor" highly expressed in male postmeiotic germ cells, is dispensable for spermatogenesis in the mouse. Mechanisms of Development 126 650-664.

Granberg F, Svensson C, Pettersson U \& Zhao H 2006 Adenovirus-induced alterations in host cell gene expression prior to the onset of viral gene expression. Virology 353 1-5.

Greenberg ME, Greene LA \& Ziff EB 1985 Nerve growth factor and epidermal growth factor induce rapid transient changes in protooncogene transcription in PC12 cells. Journal of Biological Chemistry 260 14101-14110.

Greenberg ME, Hermanowski AL \& Ziff EB 1986 Effect of protein synthesis inhibitors on growth factor activation of c-fos, c-myc, and actin gene transcription. Molecular and Cellular Biology 6 1050-1057.

Hamil KG \& Hall SH 1994 Cloning of rat Sertoli cell follicle-stimulating hormone primary response complementary deoxyribonucleic acid: regulation of TSC-22 gene expression. Endocrinology 134 1205-1212. 
Heneweer C, Kruse LH, Kindhauser F, Schmidt M, Jakobs KH, Denker HW \& Thie M 2002 Adhesiveness of human uterine epithelial RL95-2 cells to trophoblast: rho protein regulation. Molecular Human Reproduction 8 1014-1022.

Herschman HR 1991 Primary response genes induced by growth factors and tumor promoters. Annual Review of Biochemistry 60 281-319.

Jiang J, Chan YS, Loh YH, Cai J, Tong GQ, Lim CA, Robson P, Zhong S \& Ng HH 2008 A core Klf circuitry regulates self-renewal of embryonic stem cells. Nature Cell Biology 10 353-360.

Johnston DS, Jelinsky SA, Bang HJ, DiCandeloro P, Wilson E, Kopf GS \& Turner TT 2005 The mouse epididymal transcriptome: transcriptional profiling of segmental gene expression in the epididymis. Biology of Reproduction 73 404-413.

Katz JP, Perreault N, Goldstein BG, Lee CS, Labosky PA, Yang VW \& Kaestner KH 2002 The zinc-finger transcription factor KIf4 is required for terminal differentiation of goblet cells in the colon. Development 129 2619-2628.

Katz JP, Perreault N, Goldstein BG, Actman L, McNally SR, Silberg DG, Furth EE \& Kaestner KH 2005 Loss of Klf4 in mice causes altered proliferation and differentiation and precancerous changes in the adult stomach. Gastroenterology 128 935-945.

Klaewsongkram J, Yang Y, Golech S, Katz J, Kaestner KH \& Weng NP 2007 Kruppel-like factor 4 regulates B cell number and activation-induced B cell proliferation. Journal of Immunology 179 4679-4684.

Lau LF \& Nathans D 1987 Expression of a set of growth-related immediate early genes in BALB/c $3 T 3$ cells: coordinate regulation with c-fos or c-myc. PNAS 84 1182-1186.

Li Y, McClintick J, Zhong L, Edenberg HJ, Yoder MC \& Chan RJ 2005 Murine embryonic stem cell differentiation is promoted by SOCS-3 and inhibited by the zinc finger transcription factor Klf4. Blood 105 635-637.

Liu Y, Wang J, Yi Y, Zhang H, Liu J, Liu M, Yuan C, Tang D, Benjamin IJ \& Xiao X 2006 Induction of KLF4 in response to heat stress. Cell Stress and Chaperones 11 379-389.

Loss ES, Jacobus AP \& Wassermann GF 2007 Diverse FSH and testosterone signaling pathways in the Sertoli cell. Hormone and Metabolic Research 39 806-812.

Maallem S, Wierinckx A, Lachuer J, Kwon MH \& Tappaz ML 2008 Gene expression profiling in brain following acute systemic hypertonicity: novel genes possibly involved in osmoadaptation. Journal of Neurochemistry 105 1198-1211.

Mahatan CS, Kaestner KH, Geiman DE \& Yang VW 1999 Characterization of the structure and regulation of the murine gene encoding gut-enriched Kruppel-like factor (Kruppel-like factor 4). Nucleic Acids Research 27 4562-4569.

Mao D, Warner EA, Gurwitch SA \& Dowd DR 1998 Differential regulation and transcriptional control of immediate early gene expression in forskolin-treated WEHI7.2 thymoma cells. Molecular Endocrinology 12 492-503.

Mason AJ, Hayflick JS, Zoeller RT, Young WS III, Phillips HS, Nikolics K \& Seeburg PH 1986 A deletion truncating the gonadotropin-releasing hormone gene is responsible for hypogonadism in the hpg mouse. Science 234 1366-1371.

Mather JP 1980 Establishment and characterization of two distinct mouse testicular epithelial cell lines. Biology of Reproduction 23 243-252.

McLean DJ, Friel PJ, Pouchnik D \& Griswold MD 2002 Oligonucleotide microarray analysis of gene expression in follicle-stimulating hormonetreated rat Sertoli cells. Molecular Endocrinology 16 2780-2792.

Molina CA, Foulkes NS, Lalli E \& Sassone-Corsi P 1993 Inducibility and negative autoregulation of CREM: an alternative promoter directs the expression of ICER, an early response repressor. Cell 75 875-886.

Monaco L, Foulkes NS \& Sassone-Corsi P 1995 Pituitary follicle-stimulating hormone (FSH) induces CREM gene expression in Sertoli cells: involvement in long-term desensitization of the FSH receptor. PNAS 92 10673-10677.

Monaco L, Kotaja N, Fienga G, Hogeveen K, Kolthur US, Kimmins S, Brancorsini S, Macho B \& Sassone-Corsi P 2004 Specialized rules of gene transcription in male germ cells: the CREM paradigm. International Journal of Andrology 27 322-327.
Mruk DD \& Cheng CY 2004 Sertoli-Sertoli and Sertoli-germ cell interactions and their significance in germ cell movement in the seminiferous epithelium during spermatogenesis. Endocrine Reviews 25 747-806.

Myers M, Ebling FJ, Nwagwu M, Boulton R, Wadhwa K, Stewart J \& Kerr JB 2005 Atypical development of Sertoli cells and impairment of spermatogenesis in the hypogonadal (hpg) mouse. Journal of Anatomy 207 797-811.

Okita K, Ichisaka T \& Yamanaka S 2007 Generation of germline-competent induced pluripotent stem cells. Nature 448 313-317.

Panigada M, Porcellini S, Sutti F, Doneda L, Pozzoli O, Consalez GG, Guttinger M \& Grassi F 1999 GKLF in thymus epithelium as a developmentally regulated element of thymocyte-stroma cross-talk. Mechanisms of Development 81 103-113.

Raymond CS, Murphy MW, O'Sullivan MG, Bardwell VJ \& Zarkower D 2000 Dmrt1, a gene related to worm and fly sexual regulators, is required for mammalian testis differentiation. Genes and Development 14 2587-2595.

Richards JS 2001 New signaling pathways for hormones and cyclic adenosine $3^{\prime}, 5^{\prime}$-monophosphate action in endocrine cells. Molecular Endocrinology 15 209-218.

Rogers S, Wells R \& Rechsteiner M 1986 Amino acid sequences common to rapidly degraded proteins: the PEST hypothesis. Science 234 364-368.

Rowland BD \& Peeper DS 2006 KLF4, p21 and context-dependent opposing forces in cancer. Nature Reviews. Cancer 6 11-23.

Rowland BD, Bernards R \& Peeper DS 2005 The KLF4 tumour suppressor is a transcriptional repressor of p53 that acts as a context-dependent oncogene. Nature Cell Biology 7 1074-1082.

Sadate-Ngatchou PI, Pouchnik DJ \& Griswold MD 2004 Folliclestimulating hormone induced changes in gene expression of murine testis. Molecular Endocrinology 18 2805-2816.

Sassone-Corsi P 1998 Coupling gene expression to cAMP signalling: role of CREB and CREM. International Journal of Biochemistry and Cell Biology 30 27-38.

Segre JA, Bauer C \& Fuchs E 1999 Klf4 is a transcription factor required for establishing the barrier function of the skin. Nature Genetics 22 356-360.

Shields JM, Christy RJ \& Yang VW 1996 Identification and characterization of a gene encoding a gut-enriched Kruppel-like factor expressed during growth arrest. Journal of Biological Chemistry 271 20009-20017.

Sun N, Panetta NJ, Gupta DM, Wilson KD, Lee A, Jia F, Hu S, Cherry AM, Robbins RC, Longaker MT et al. 2009 Feeder-free derivation of induced pluripotent stem cells from adult human adipose stem cells. PNAS 106 15720-15725.

Swamynathan SK, Katz JP, Kaestner KH, Ashery-Padan R, Crawford MA \& Piatigorsky J 2007 Conditional deletion of the mouse Klf4 gene results in corneal epithelial fragility, stromal edema, and loss of conjunctival goblet cells. Molecular and Cellular Biology 27 182-194.

Tai TC, Morita K \& Wong DL 2001 Role of Egr-1 in cAMP-dependent protein kinase regulation of the phenylethanolamine $\mathrm{N}$-methyltransferase gene. Journal of Neurochemistry 76 1851-1859.

Walker WH \& Cheng J 2005 FSH and testosterone signaling in Sertoli cells. Reproduction 130 15-28.

Wernig M, Meissner A, Foreman R, Brambrink T, Ku M, Hochedlinger $K$, Bernstein BE \& Jaenisch R 2007 In vitro reprogramming of fibroblasts into a pluripotent ES-cell-like state. Nature 448 318-324.

Yoon HS \& Yang VW 2004 Requirement of Kruppel-like factor 4 in preventing entry into mitosis following DNA damage. Journal of Biological Chemistry 279 5035-5041.

Zhang X, Odom DT, Koo SH, Conkright MD, Canettieri G, Best J, Chen H, Jenner R, Herbolsheimer E, Jacobsen E et al. 2005 Genome-wide analysis of cAMP-response element binding protein occupancy, phosphorylation, and target gene activation in human tissues. PNAS 102 4459-4464.

Zhao W, Hisamuddin IM, Nandan MO, Babbin BA, Lamb NE \& Yang VW 2004 Identification of Kruppel-like factor 4 as a potential tumor suppressor gene in colorectal cancer. Oncogene 23 395-402.

Received 27 November 2009

First decision 5 January 2010

Accepted 5 January 2010 